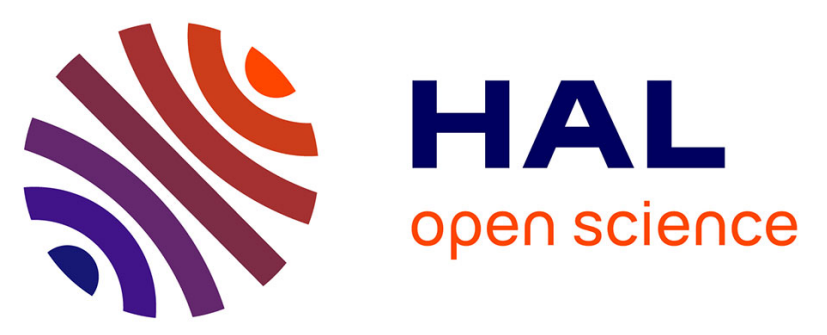

\title{
Minimum 10-Year Outcome of One-Stage Total Hip Arthroplasty Without Subtrochanteric Osteotomy Using a Cementless Custom Stem for Crowe III and IV Hip Dislocation
}

Olivier Freddy Hitz, Xavier Flecher, Matthieu Ollivier, Sebastien Parratte, Jean-Noël Argenson

\section{To cite this version:}

Olivier Freddy Hitz, Xavier Flecher, Matthieu Ollivier, Sebastien Parratte, Jean-Noël Argenson. Minimum 10-Year Outcome of One-Stage Total Hip Arthroplasty Without Subtrochanteric Osteotomy Using a Cementless Custom Stem for Crowe III and IV Hip Dislocation. The Journal of Arthroplasty, 2018, 33 (7), pp.2197-2202. 10.1016/j.arth.2018.02.055 . hal-01960504

\section{HAL Id: hal-01960504 https://hal.science/hal-01960504}

Submitted on 9 May 2019

HAL is a multi-disciplinary open access archive for the deposit and dissemination of scientific research documents, whether they are published or not. The documents may come from teaching and research institutions in France or abroad, or from public or private research centers.
L'archive ouverte pluridisciplinaire HAL, est destinée au dépôt et à la diffusion de documents scientifiques de niveau recherche, publiés ou non, émanant des établissements d'enseignement et de recherche français ou étrangers, des laboratoires publics ou privés. 


\title{
Minimum 10-Year Outcome of One-Stage Total Hip Arthroplasty Without Subtrochanteric Osteotomy Using a Cementless Custom Stem for Crowe III and IV Hip Dislocation
}

\author{
Olivier Freddy Hitz, MD a, b, Xavier Flecher, MD, PhD b, c, ${ }^{*}$, Sebastien Parratte, MD, PhD b, c, \\ Matthieu Ollivier, MD, PhD b, c, Jean-Noel Argenson, MD, PhD b, c \\ ${ }^{a}$ Lausanne University, Lausanne, Switzerland \\ ${ }^{\mathrm{b}}$ Department of Orthopedic Surgery and Traumatology, Institute for Locomotion, St. Marguerite Hospital, Marseille, France \\ ${ }^{c}$ Aix-Marseille University, CNRS, ISM UMR 7287, Marseille Cedex 09, France
}

\begin{abstract}
a bs tract
Background: Options for total hip arthroplasty (THA) in high dislocated hips include subtrochanteric osteotomy (STO), high hip center positioning, and 2-stage surgery with progressive lowering using an external fixator before THA. We described the long-term results of 1-stage THA performed without STO, using a cementless customized stem associated if necessary with sequential tenotomies and/or greater trochanteric osteotomy.

Methods: Ninety-eight consecutive THA without STO were performed using this technique. Of those 98 hips, 26 hips with high dislocation (12 class III and 14 class IV according to the Crowe classification) were evaluated at an average follow-up of 16 (10-22) years.

Results: At the time of last follow-up, the mean Harris Hip Score was 86 points (37-100). The mean leglength discrepancy was $7 \pm 5 \mathrm{~mm}(0-17)$. Two transient $(7.7 \%)$ nerve palsies ( 1 sciatic and 1 femoral) were notified. A revision was required for 6 hips (23.1\%). Kaplan-Meier survivorship analysis at 15 years regarding aseptic loosening of the femoral component was $87.5 \%$ (95\% confidence interval, 76.5-99.1). During the same period, acetabular implant survivorship free from revision for aseptic loosening was 96.1\% (95\% confidence interval, 92.7-99.9).

Conclusion: The combination of intramedullary fit and extramedullary adaptation for offset and anteversion provided by the custom stem can avoid additional procedures associated to THA in high developmental dysplasia of the hip. The clinical function and long-term survival reported in this series is encouraging for THA performed in case of high hip dislocation.
\end{abstract}

Total hip arthroplasty (THA) for neglected developmental dysplasia of the hip (DDH) is a technically demanding procedure for arthroplasty surgeons [1e3]. The placement of the acetabular component in the true acetabulum is considered to be the ideal choice for biomechanical and biological reasons [4e12]. It can, thus, be challenging to reduce the hip joint and achieve leg-length

\footnotetext{
One or more of the authors of this paper have disclosed potential or pertinent conflicts of interest, which may include receipt of payment, either direct or indirect, institutional support, or association with an entity in the biomedical field which may be perceived to have potential conflict of interest with this work. For full disclosure statements refer to https:/ / doi.org/10.1016/j.arth.2018.02.055.

* Reprint requests: Xavier Flecher, MD, PhD, Department of Orthopedic Surgery and Traumatology, Institute for Locomotion, St. Marguerite Hospital, 270 Boulevard Sainte Marguerite, BP 29, Marseille 13274, France.
}

restoration while avoiding neurologic traction injury $[13,14]$. Therefore, to overcome contractures and to reduce the hip without stretching the sciatic nerve, femoral shortening has been introduced by Paavilainen et al [15] and Eskelinen et al [16] as an adjunct to THA. Several authors havereported long-term results of THA for high DDH performed using shortening osteotomy [16e21]. Toavoid the complications related to osteotomy, recent reports documented 2-stage progressive femoral lowering followed by a cementless THA (Yoon et al [22], Binazzi [23]). However, only few papers have documented the long-term results of isolated cementless THA in such etiology (Crowe III and IV) [24,25] and none using isolated custom stems. In the review by Tsiampas et al [26], the long-term series mentioned in the article with custom-made femoral implants was not only focused on high DDH but also combined femoral shortening osteotomy was used intermittently. The 
purpose of the present retrospective study is to report the clinical and radiographic minimum 10-year outcome of THA for Crowe III and IV DDH using a customized stem without shortening osteotomy, associated with sequential tenotomies and/or greater trochanter osteotomy if needed.

\section{Methods}

\section{Patients}

Ninety-eight one-stage THAs for late DDH (82 patients) were performed at a single institution. The Croweclassification has been used to assess the magnitude of subluxation of the femoral head [14]. This classification includes 4 types: I ( $<50 \%$ subluxation), II (50e75\% subluxation), III (75e100\% subluxation), and IV (100\% subluxation). Of those 98 hips, 26 hips ( 23 patients) were classified according to the Crowe classification as type III (n⿳1⿴囗十一⿺辶12) and IV (n 4 ) and were followed up from 1990 to 2013. There were 18 females and 5 males. The mean age at the time of the procedure was $45 \pm 12.3$ (17-63) years. The average height was $160 \pm 6.2$ (150$170) \mathrm{cm}$, and the average weight was $69 \pm 12.8(46-118) \mathrm{kg}$. There were 13 left hips and 13 right hips. Thirteen hips (50\%) had a previous surgery on the considered hip, including 6 shelf arthroplasties, 5 intertrochanteric osteotomies, 1 open reduction, and 1 Chiari pelvic osteotomy. The mean follow-up was 16 (10-22) years.

\section{Preoperative Planning}

The preoperative planning included anteroposterior (AP) pelvic view, AP and lateral view of the considered hip, full frontal view of the lower limbs, positioning the patient supine, and a computed tomography (CT) scan. A 3-dimensional reconstruction of the internal and external geometry of the femur was created based on digital imaging and communications in medicine format images obtained from a CT scan that included the acetabular roof proximally to the posterior femoral bicondylar axis distally $[27,28]$. In presence of structural changes in the lumbosacral spine, malalignment of the ipsilateral knee and/or equinus foot, a lateral view of the lower limbs was obtained. The mean preoperative leg-length discrepancy (LLD) was $36 \pm 26$ (3-80) $\mathrm{mm}$. According to the Crowe classification, the mean preoperative LLD was $27 \pm 20(3$ to 60$) \mathrm{mm}$ and $45 \pm 29(5-80) \mathrm{mm}$, respectively, in type III and IV (1/2 .003). Taking into account the spine, knee, and/or foot abnormalities, the desired lengthening was $32 \pm 26$ (3-80) $\mathrm{mm}$, with $24 \pm 18$ (3 to 58) $\mathrm{mm}$ and $45 \pm 29$ (5 to 80 ) $\mathrm{mm}$ for Crowe type III and IV, respectively $(P 1 / 4$.004). The mean preoperative anteversion of the proximal femur was $21^{0} \pm 13^{0}\left(8^{0}-46^{0}\right)$.

\section{Surgical Technique}

All the procedures were performed under general anesthesia by a senior surgeon using the anterolateral Watson-Jones approach in supine position without a traction table. Greater trochanteric osteotomy (GTO) was performed in 6 hips (23\%) with lateral repositioning when excessive femoral anteversion was present to relocate the abductor muscles action lineand avoid a posterior position. Sequential tenotomies were performed if needed forlowering of the femur including adductor or iliopsoas tenotomy ( $22 \mathrm{hips}, 85 \%$ ). Once the psoas insertion was released, the femoral head-neck resection could be performed at the level of the lesser trochanter to ensure a complete capsule detachment. No abductor or fascia lata muscles release, intertrochanteric shortening or rotational femoral osteotomy was performed, and no external fixator was used. Nosciatic nerve tension assessment or release was performed. In all cases, an hemispheric press-fit uncemented titanium alloy, hydroxyapatite
(HA)-coated acetabular component (Hilock Rev, Symbios, Yverdon, Switzerland) was implanted in the true acetabulum with a hook placed in the obturator foramen and 2 screws in the acetabular roof. Autogenous femoral head grafts were used to provide additional superolateral acetabular coverage in 7 hips (27\%), 3 in Crowe III (3 of $12,25 \%$ ), and 4 in Crowe IV (4 of 14, 29\%). A conventional ultra-highweight polyethylene $20^{\circ}$ elevated liner was used in association with a ceramic head. The average diameter of the cup was 46 (36-56) $\mathrm{mm}$. A 3-dimensional cementless custom HA-coated titanium femoral component (Symbios, Yverdon, Switzerland) has been used for all patients fitting the intramedullary proximal femoral anatomy and accommodating the 3-dimensional offset of the femoral neck to obtain the correct hip center $[3,27,29]$. GTO, when performed, was stabilized with 3 cerclages with the lower limb in abduction. After skin closure and wound management, a pillow was used to position the lower limb in abduction and flexion, when an intraoperative contracture was present after THA reduction. Neurologic and vascular complications were immediately assessed in the recovery room.

\section{Postoperative Management}

All patients were mobilized on the first day after THA, sitting on bed. On the second day, they were asked to stand up, helped by a physiotherapist, and on the third day, they were allowed to walk with partial weight bearing protected by 2 crutches. The 2 crutches were used for 6 weeks in case of greater trochanter osteotomy, without active abduction workout, and for 3 weeks, when no greater trochanter osteotomy was performed, and a single crutch on the opposite side was required for 3 additional weeks. No brace was used. Exercises focused on passive and then active recuperation of ROM. Routine thromboprophylaxis was used with lowmolecular-weight heparin preoperatively and postoperatively for 3 weeks.

\section{Clinical and Radiographic Evaluations}

Clinical evaluation was performed using the Harris Hip Score (HHS) [30] preoperatively and postoperatively. A 5-scale satisfaction score was used (patients rated their hip status as excellent, good,fair, poor, and disappointing). The presence of intraoperative or postoperative complications including infection, nerve palsy, dislocations, or loosening was recorded. Standard AP and lateral radiographs performed at the most recent follow-up examination were compared with the first postoperative radiographs. The assessment criteria were the osteointegration of the femoral componentaccording toEngh and Bobyn [31],radiolucentlinesand periprosthetic osteolysis in the femur according to the 7 zones from the study by Gruen et al [32], the presence of radiolucent lines at the acetabular-boneinterfaceaccording toDeLeeandCharnley [33], the stability of the acetabular component as described by Zicat et al [34] in each of the 3 zones from the study by DeLee and Charnley [33], the acetabular graft osteointegration according to Conn et al [35], the grade of heterotopic ossification according to Brooker et al [36], and the fusion at the site of greater trochanter repositioning.

\section{Statistical Methods}

Data are presented as mean values with ranges. The Student's $t$ test was used for comparisons of continuous variables. $P$ value $<.05$ was significant. Kaplan-Meier survivorship analysis [37] was performed with 2 end points: (1) revision for any reason and (2) revision for aseptic loosening, mechanical failure, or wear. Statistical analysis was performed using SPSS software (IBM, Armonk, New York). 


\section{Results}

The mean HHS of the 23 patients ( 26 hips) increased significantly from preoperative $(49 \pm 22$ points $)$ to the most recent followup examination ( $86 \pm 13$ points; $P<.0001)$. At the last follow-up, the mean HHS pain subscore was $41 \pm 5$ points, with 20 hips $(77 \%)$ showing no pain. Seventeen patients $(74 \%)$ walked without any aid. Ten hips (38.5\%) did not show any limping, 10 (38.5\%) had a slight, $5(19.2 \%)$ a moderate, and $1(3.8 \%)$ a severe limping. Using the subjective satisfaction self-evaluation, 15 patients (65\%) rated their results as excellent and $8(35 \%)$ as good. No correlation was found between patients using a walking aid, limping, and their satisfaction evaluation.

The mean LLD was $7 \pm 5(0-17) \mathrm{mm}$. There were $2(7.7 \%)$ transient nerve palsies ( 1 sciatic and 1 femoral). The sciatic nerve palsy was recorded in a 38-year-old female with a bilateral Crowe IV DDH that had a previous shelf arthroplasty only on the right side. She underwent 2 sequential THAs with planed lengthening of $48 \mathrm{~mm}$ on the right side and $53 \mathrm{~mm}$ on the left side. The nerve palsy was recorded on the right side and resolved completely at 18 months. The HHS was 87 at the final follow-up, and the satisfactory evaluation was rated as good. The second was a femoral palsy which resolved in 11 months. It was a 51-year-old female with a right Crowe IV DDH and a lengthening to be realized of $29 \mathrm{~mm}$. She did not have previous surgery on the considered hip. The HHS was 88 at the final follow-up, and the satisfactory evaluation was rated as good.

Two patients $(8.7 \%)$ had recurrent hip dislocations. The first one was a 63-year-old woman with a left Crowe III DDH. She was treated by repositioning of the elevated liner and did not have any other subsequent dislocation. The final HHS was 77 and her satisfaction evaluation was rated as good. The second one was a 17-yearold female who underwent a THA for a Crowe III DDH who required an early cup revision for better positioning. The final HHS was 97 points, and the satisfaction evaluation was rated as good. One hip $(3.8 \%)$ had a symptomatic greater trochanter nonunion which required an open reduction and internal fixation. The final HHS was 91, but a crutch was required to walk. All the acetabular components were located in the true acetabulum without detectable migration (Fig. 1).

The radiographic analysis at the last follow-up showed a nonprogressive radiolucent line around the acetabular component in zone 1 in 1 hip (3.8\%) according to DeLee and Charnley [33]. An asymptomatic femoral osteolysis was present in 2 hips $(7.7 \%)$ in zone 1 according to Gruen [32]. Heterotopic ossifications were observed in 1 hip (3.8\%) and were classified as grade 1 according to Brooker et al [36]. No pronounced resorption was noted around the femoral components according to Engh and Bobyn [31]. All acetabular components were considered as stable according to Zicat et al [34]. All cases with acetabular graft showed a good osteointegration according to Conn et al [35].

A revision was needed in 6 hips (23.1\%). In addition to the early cup revision for instability mentioned previously, 1 cup was revised for aseptic loosening at 95 months. In 3 hips (11.5\%), the stem was revised: 1 for a Vancouver B2 fracture (acute trauma) and $2(7.7 \%)$ for aseptic loosening at 111 and 161 months. In 1 hip (3.8\%), the liner was changed for symptomatic wear at 132 months.

Kaplan-Meier survivorship analysis at 15 years of the femoral component considering revision for aseptic loosening as the end point was $87.5 \%$ (95\% confidence interval, 76.5-99.1) (Fig. 2). For the acetabular implant considering aseptic loosening as the end point, survivorship was 96.1\% (95\% confidence interval, 92.7-99.9) (Fig. 3). Survivorship analysis at 15 years for both implants was $72.6 \%(95 \%$ confidence interval, 45.3-99.9) regarding any reason as the end point. The number of hips at risk for revision was 10 at 15 years.

\section{Discussion}

Several techniques have been described to address end-stage osteoarthritis in Crowe type III or IV DDH using THA. The key aspect for achieving long-term stability of the acetabular component relies on excellent coverage of the cup and restoration of the center of rotation of the hip into an anatomical position [7]. Linde et al [38] reported that at a mean follow-up of 9 years, the placement of the acetabular component in the true acetabulum produced a much lower loosening rate than placement above the true acetabulum (13\% and $42 \%$, respectively). Pagnano et al [8] found that positioning of the cup proximal to the true acetabular region was associated with substantial increase in loosening. These observations indicate that the acetabular component should be positioned in the true acetabular region in patients with high $\mathrm{DDH}$. The present study, using a 1-stage surgical technique without subtrochanteric osteotomy (STO), has shown that all the acetabular components were located in the true acetabulum without detectablemigration and a $96.1 \%$ cup survival at 15 years of follow-up. The
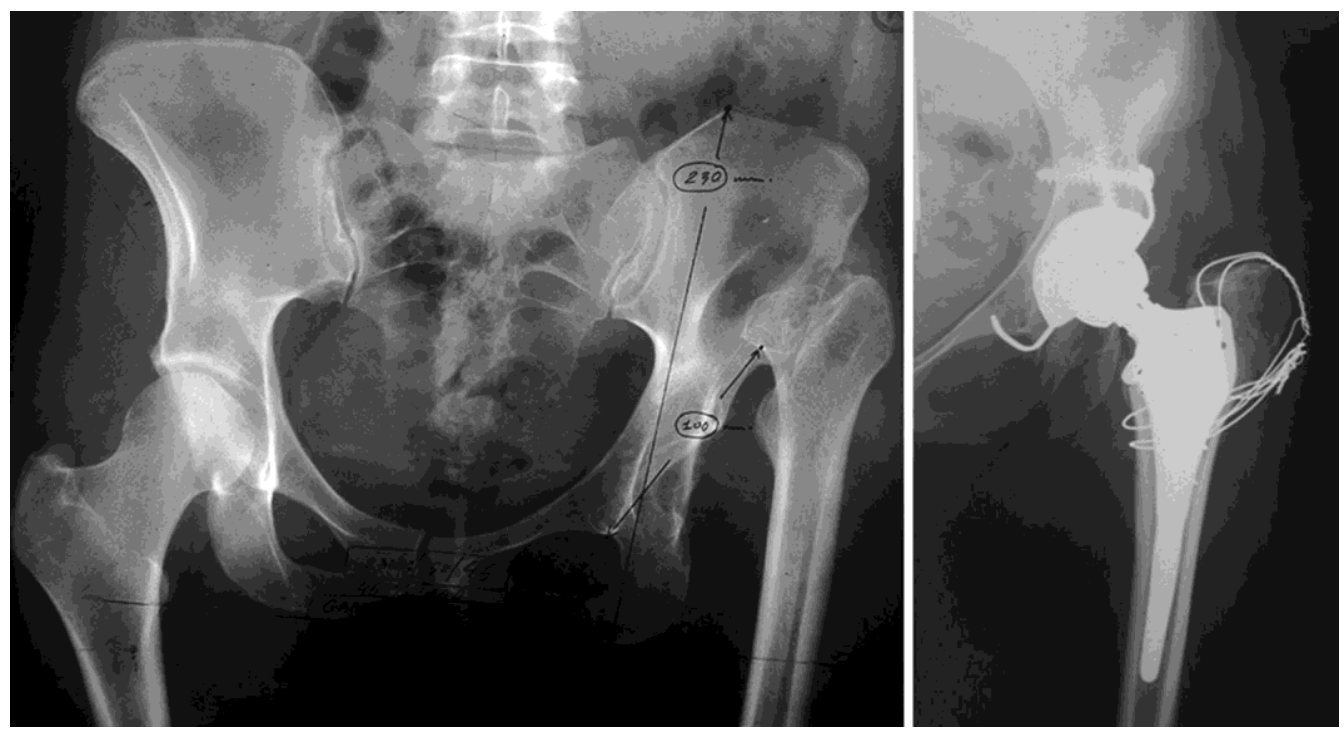

Fig. 1. Crowe IV DDH with greater trochanter osteotomy and 38-mm lengthening. 


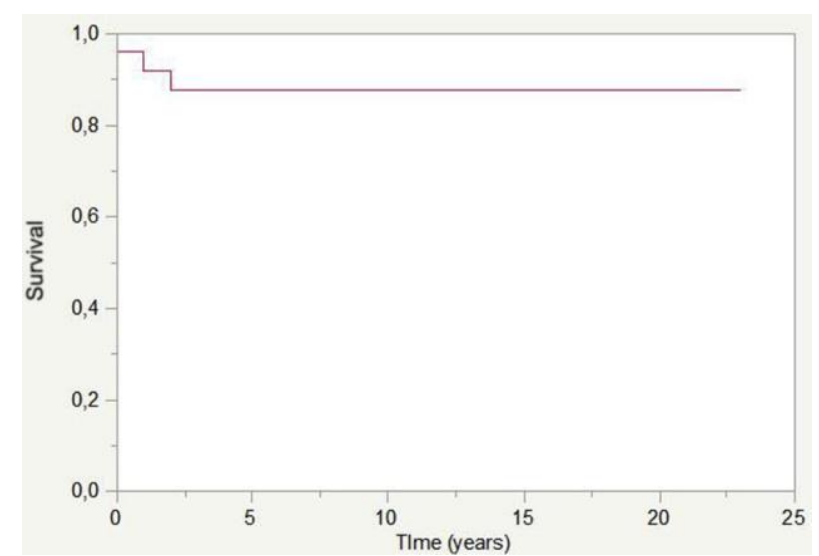

Fig. 2. Kaplan-Meier curve showing $87.5 \%$ survivorship free from stem revision regarding aseptic loosening at 15 years.

custom stem used in this series of THA for high hip dislocation provides anatomical fit and 3D neck correction for anticipating surgical difficulties found in this etiology related to proximal femoral anatomy. The clinical results are encouraging in a young and active population while exhibiting satisfactory lower limb equalization and limited neurological complications.

Anatomic socket placement can make hip reduction difficultand reduction may require considerable limb lengthening associated with increased risk of neurological injury [13,14]. Therefore, femoral shortening has been proposed to facilitate reduction and protect the sciatic and femoral nerves. It is a 1-stage technique, using the femoral component for intramedullary stabilization that also allows for correction of a severe anteversion of the femoral neck. However, the procedure remains challenging as incongruences may appear between the proximal and distal canal diameters after shortening osteotomy leading to difficulties for achieving a secure fixation; these difficulties might increase the risk of delayed union or nonunion of the osteotomy $[18,27,29,39$ e41]. While Ollivier et al [19] mentioned for Crowe IV patients a nonunion rate at femoral shortening osteotomy site of $7 \%$, Mutlu et al [42] reported in Crowe III and IV patients either $18.6 \%$ nonunion or $20.9 \%$ delayed union depending on the type of cementless stem used. Kawai et al [43] using cemented stems mentioned an average time to union of the osteotomy site of 4.9 (38) months and that full weight bearing was allowed after 12-16 weeks. Using cementless stems, weight bearing is usually carefully increased depending on the consolidation of the osteotomy site

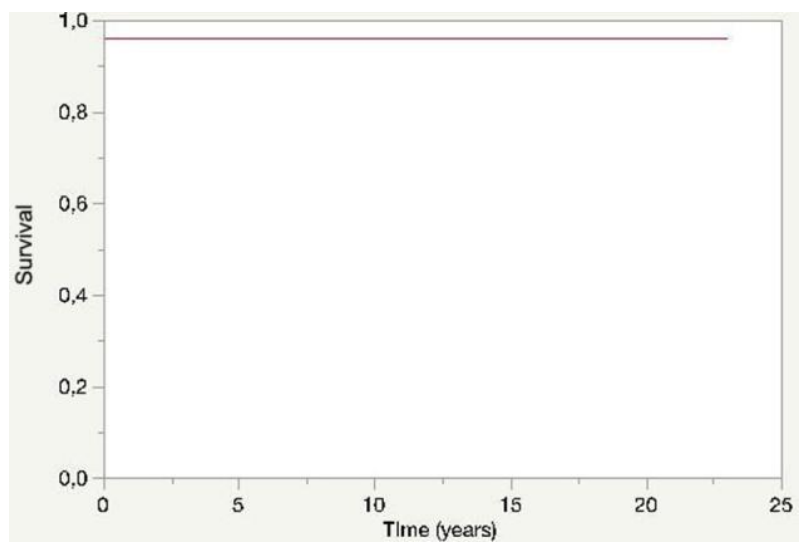

Fig. 3. Kaplan-Meier curve showing $96.1 \%$ survivorship free from cup revision regarding aseptic loosening at 15 years. starting at 6 weeks and fully completed at 12 weeks according to several authors $[16,17,44 \mathrm{e} 47]$. In the present series without STO, patients were allowed to walk with partial weight bearing at day 3 with the help of 2 crutches and full weight bearing was normally applied after 3 weeks if a GTO was performed.

Additional complications related to the procedure have been described as nerve palsies [39e $41,48,49]$, intraoperative femoral fracture [13,18,29], and dislocation [13,18,40,41,49]. Mu et al [50] using cementless Zweymüller THA with STO in 71 Crowe IV patients mentioned 1 case of complete and 7 cases of transient nerve palsies, 1 cup loosening, 4 polyethylene wear and 1 cup breakage, 1 dislocation, and 20 intraoperative fractures. In the present series using custom stems, we did not find any intraoperative fracture, probably in relation with the adaptation between the stem and the proximal modified anatomy often found in such etiology. However, the major concern described with the shortening osteotomy technique remains the residual postoperative LLD especially if the DDH is unilateral $[13,40,49]$. The average $7(0-17) \mathrm{mm}$ postoperative mean LLD reported in the present series using a custom femoral stem is close to the $6(0-20) \mathrm{mm}$ reported by Ollivier et al [19] but compares favorably with the other series associating a STO and reporting average LLD from 12 to $14 \mathrm{~mm}$ with maximum values ranging from 0 to $60 \mathrm{~mm}[16,17,45 \mathrm{e} 47]$.

Long-term results of THA for high DDH with shortening osteotomy showed heterogeneous results. Eskelinen et al [16] followed up 64 hips and reported a 10-year survival rate of $98.4 \%$ for the stem and $94.9 \%$ for the porous-coated cup, but 8 of the 9 threaded cups were revised. Hartofilakidis and Karachalios [9] followed up 84 hips with cemented or uncemented cups and cemented stems and reported an overall 15-year survival rate of $82.5 \%$ for the stem and $86.1 \%$ for the cup. Ollivier et al [19] reviewed 28 hips (24 cementless, 4 cementless modular stem and cementless cup) with a mean follow-up of 10 years and reported a 10-year survivorship of the components free of revision of $82 \%$. Reikeras et al [17] followed up 64 hips with uncemented components (straight conical stem full HA and HA or titanium porous-coated cup) at a mean follow-up of 13 years and reported a 15-year survival for any reason of $75 \%$ for the cup and $100 \%$ for the stem. However, 1 stem subsided after 8 months and was replaced.

Regarding outcomes of THA without shortening osteotomy for Crowe III or IV hips, Kerboull et al [48] using a transtrochanteric approach and cemented components in 83 hips reported a survival rate of $78 \%$ at 16 years with revision for any reason as the end point. Numair et al [51] reported higher rates of acetabular revision in completely dislocated hips with cemented components, as compared with dysplastic hips. Chougle et al [52] reported a cup survival rate for aseptic loosening in Crowe IV hips of $60.9 \%$ at 10 years. Kawai et al [53] reported a survival rate after transtrochanteric approach and cemented THA of $96.3 \%$ at 10 years with any revision surgery as the end point. Using cementless THAs without shortening osteotomy for Crowe III or IV hips, Imbuldeniya et al [24] showed for 25 hips, a survival with revision for any reason of $81 \%$ at 15 years with $57 \%$ of the patients who had a revision of the acetabular component secondary to polyethylene wear.Proximal osteolysis in zone 1 or 7 around the femoral stem was found in 10 of the 25 hips, all implanted with modular S-ROM stems. Lee et al [25] reported in 27hips with GTO and various types of cups and stems at a mean follow-up of 15.1 years, a mean LLD of $10 \mathrm{~mm}, 2$ transient peroneal nerve palsies and 2 permanent neurologic deficits (1 femoral, 1 sciatic), 3 intraoperative fractures, and a survival rate for aseptic loosening at 15 years of $90.9 \%$ for stem and $52.3 \%$ for cup. The use of custom-made stem has been described mostly for low-grade DDH patients [54e56] or with short-term follow-up [57] or were indicated for various femoral deformity etiologies [58]. Benum and Aamodt [55] using occasional subtrochanteric 
osteotomies for lengthening reported no case of stem aseptic loosening at 10-year follow-up. Akbar et al [58] reported cup loosening of 5 cups in 72 hips with any progressive femoral osteolysis after a mean follow-up of 14 years.

Although some authors have reported that limb lengthening should be limited to $4 \mathrm{~cm}$ [59], Kerboull et al [48] reported that limb lengthening until $7 \mathrm{~cm}$ was possible. In our study using an anterolateral approach with sequential tenotomies, it was always possible to reduce the hip into the true acetabulum without the need for a femoral shortening, including the 19 hips (73\%) that had a lengthening superior to $4 \mathrm{~cm}$. Two $(7.7 \%)$ nerve palsies were documented and both recovered. Another option is to perform a 2stage progressive femoral lengthening followed by a cementless THA. Binazzi [23] documented the clinical radiographic results of 11 patients (12 hips) who were operated with a 2-stage technique at a mean follow-up of $11 \pm 5$ years with no neurovascular damage or a need for femoral internal fixation and complete limb symmetry. However, 1 hip ( $8.3 \%$ ) had a remaining postoperative LLD of $1.8 \mathrm{~cm}$. A potential increased risk of infection remains, owing to the use of an external fixator, and the hospital stay was increased by 2 weeks, corresponding to the time needed for lengthening before the second stage. Yoon et al [22] described a 2-stage operation planned in 6 irreducible hips when expected lengthening of the affected limb after THA was superior to $2.5 \mathrm{~cm}$ or when flexion contracture was superior to $30^{\circ}$. Surgical hip release with abductor slide, tensor fascia lata, sartorius muscle, iliopsoas tendon, and rectus femoris release was performed through 2 skin incisions during the first stage. Gradual skeletal traction was thus applied to the operated limb for 2 weeks before performing the THA. However, 5 of 6 hips $(83 \%)$ were difficult to reduce requiring a subtrochanteric shortening osteotomy to prevent neurologic traction injuries. In the lengthening technique described in the present series, tenotomies of either the adductors or psoas were performed sequentially to reduce the risk of neurological complications. In our experience, a complete muscle function for active flexion and abduction was achieved 6 months after surgery. Eggli et al [60] mentioned that most nerve lesions after leg lengthening occurred by direct or indirect trauma to the nerve during surgery. The incidence of permanent nerve lesion seemed higher without STO in the study by Sonohata et al [61], but nerve palsies are also present with STO techniques. A recent study by $\mathrm{Li}$ et al [62] compared 2 groups of Crowe IV patients who underwent cementless THA, one with (20 hips) and one without (22 hips) subtrochanteric shortening osteotomy. The group without femoral shortening osteotomy had a lower postoperative mean LLD and a lower number of patients who developed a limp, more transient femoral nerve palsy $(3$, all reversible after 6 months), and more knee valgus deformity due to tight soft tissue/iliotibial tract (mostly reversible at the end of follow-up after stretching). The group with osteotomy had one intraoperative fracture and one delayed union at osteotomy site. No sciatic nerve palsy or dislocation was recorded in both groups.

The mean postoperative HHS in the present series using a custom monoblock cementless stem was 86 , and the survival at 15 years regarding aseptic loosening was $87.5 \%$ for the stem and $96.1 \%$ for the cup, all of them implanted in the true acetabulum in a series of Crowe III and IV dislocated hips. The 3D evaluation of the proximal femur anatomy in high DDH $[1,27]$ has shown several important modifications the orthopedic surgeon has to face at the time of THA in such patients compared to primary osteoarthritis $[28,29]$. The use of custom stem allows fast weight bearing and quick rehabilitation program. Nowadays, the routine use of preoperative CT planning is largely accepted to better assess the 3D anatomy in complex degenerative or traumatic cases to anticipate difficulties during surgery like in THA for high DDH. The $20 \%$ additional cost of the custom stem, when compared to off-the-shelf anatomical implant, is hopefully compensated by the reduced length of stay related to immediate weight bearing and the early recovery. This extra cost is also reduced because there is no need for ancillary tools. The 15-year survival, with stable clinical improvement, is encouraging in a group of young patients with a mean age of 45 years, implanted with THA for osteoarthritis secondary to high DDH.

This study has some limitations, including the limited number of patients and its retrospective design; however, THA for high DDH do represent an uncommon and challenging situation for which large prospective studies with a long follow-up are not available. Despite these limitations, the present series is the longest series to date investigating the outcome of cementless THA without shortening osteotomy using a custom stem combined with sequential tenotomies in patients with a high hip dislocation secondary to DDH.

\section{References}

[1] Argenson JN, Flecher X, Parratte S, Aubaniac JM. Anatomy of the dysplastic hip and consequences for total hip arthroplasty. Clin Orthop Relat Res 2007:465:40e5.

[2] Liu H, Xu N, Zhang Y, Gu Y, Sun J, Tong J. Morphological study on proximal femur in adult patients with Crowe type IV developmental dysplasia of the hip and its clinical significance. Zhongguo Xiu Fu Chong Jian Wai Ke Za Zhi 2015;29:931e5.

[3] Flecher X, Parrate S, Aubaniac JM, Argenson JN. Three-dimensional custom designed cementless femoral stem for osteoarthritis secondary to congenital dislocation of the hip. J Bone Joint Surg Br 2007;89:1586e91.

[4] Linde F, Jensen J. Socket loosening in arthroplasty for congenital dislocation of the hip. Acta Orthop Scand 1988;59:254e7.

[5] Yoder SA, Brand RA, Pedersen DR, O'Gorman TW. Total hip acetabular component position affects component loosening rates. Clin Orthop Relat Res 1988;228:79e87.

[6] Doehring TC, Rubash HE, Shelley FJ, Schwendeman LJ, Donaldson TK, Navalgund YA. Effect of superior and superolateral relocations of the hip center on hip joint forces. An experimental and analytical analysis. J Arthroplasty 1996;11:693e703.

[7] Flecher X, Parrate S, Brassart N, Aubaniac JM, Argenson JN. Evaluation of the hip center in total hip arthroplasty for old developmental dysplasia. J Arthroplasty 2008;23:1189e96.

[8] Pagnano W, Hanssen AD, Lewallen DG, Shaughnessy WJ. The effect of superior placement of the acetabular component on the rate of loosening after total hip arthroplasty. J Bone Joint Surg Am 1996;78:1004e14.

[9] Hartofilakidis G, Karachalios T. Total hip arthroplasty for congenital hip disease. J Bone Joint Surg Am 2004;86-A:242e50.

[10] Paavilainen T, Hoikka V, Solonen KA. Cementless total replacement for severely dysplastic or dislocated hips. J Bone Joint Surg Br 1990;72:205.

[11] Ranawat AS, Dorr LD, Inglis AE. Total hip arthroplasty in protusio acetabuli of rheumatoid arthritis. J Bone Joint Surg Am 1980;62:1059.

[12] Callaghan JJ, Salvati EA, Pellicci PM, Wilson Jr PD, Ranawat CS. Results of revision for mechanical failure after cemented total hip replacement, 1979 to 1982. A two to five year follow-up. J Bone Joint Surg Am 1985;67:1074e85.

[13] Charnley J, Feagin JA. Low-friction arthroplasty in congenital subluxation of the hip. Clin Orthop Relat Res 1973;91:98e113.

[14] Crowe JF, Mani VJ, Ranawat CS. Total hip replacement in congenital dislocation and dysplasia of the hip. J Bone Joint Surg Am 1979;61:15e23.

[15] Paavilainen T, Hoikka V, Paavolainen P. Cementless total hip arthroplasty for congenital dislocated or dysplastic hips. Technique for replacement with a straight femoral component. Clin Orthop Relat Res 1993;297:71e81.

[16] Eskelinen A, Helenius I, Remes V, Ylinen P, Tallroth K, Paavilainen T. Cementless total hip arthroplasty in patients with high congenital hip dislocation. J Bone Joint Surg Am 2006;88:80e91.

[17] Reikeras O, Haaland JE, Lereim P. Femoral shortening in total hip arthroplasty for high developmental dysplasia of the hip. Clin Orthop Relat Res 2010;468:1949e55.

[18] Hartofilakidis G, Karachalios T, Georgiades G, Kourlaba G. Total hip arthroplasty in patients with high dislocation: a concise follow-up, at a minimum of fifteen years, of previous reports. J Bone Joint Surg Am 2011;93:1614e8.

[19] Ollivier M, Abedl MP, Krych AJ, Trousdale RT, Berry DJ. Long-term results of total hip arthroplasty with shortening subtrochanteric osteotomy in Crowe IV developmental dysplasia. J Arthroplasty 2016;31:1756e60.

[20] Wang D, Li LL, Wang HY, Pei FX, Zhou ZK. Long-term results of cementless total hip arthroplasty with subtrochanteric shortening osteotomy in Crowe Type IV developmental dysplasia. J Arthroplasty 2017;32:1211e9.

[21] Kim YH, Seo HS, Kim JS. Outcomes after THA in patients with high hip dislocation after childhood sepsis. Clin Orthop Relat Res 2009;467:2371e8.

[22] Yoon PW, Kim JI, Kim DO, Yu CH, Yoo JJ, Kim HJ, et al. Cementless total hip arthroplasty for patients with Crowe type III or IV developmental dysplasia of the hip: two-stage total hip arthroplasty following skeletal traction after soft tissue release for irreducible hips. Clin Orthop Surg 2013;5:167e73. 
[23] Binazzi R. Two-stage progressive femoral lowering followed by cementless total hip arthroplasty for treating Crowe IV-Hartofilakidis Type 3 developmental dysplasia of the hip. J Arthroplasty 2015;30:790e6.

[24] Imbuldeniya AM, Walter WL, Zicat BA, Walter WK. Cementless total hip replacement without femoral osteotomy in patients with severe developmental dysplasia of the hip: minimum 15-year clinical and radiological results. J Bone Joint Surg Br 2014;96-B:1449e54.

[25] Lee SJ, Yoo JJ, Kim HJ. Cementless total hip arthroplasty involving trochanteric osteotomy without subtrochanteric shortening for high hip dislocation. Clin Orthop Surg 2017;9:19e28.

[26] Tsiampas DT, Pakos EE, Georgiadis GC, Xenakis TA. Custom-made femoral implants in total hip arthroplasty due to congenital disease of the hip: a review. Hip Int 2016;26:209e14.

[27] Argenson JN, Ryembault E, Flecher X, Brassart N, Parratte S, Aubaniac JM. Three- dimensional anatomy of the hip in osteoarthritis after developmental dysplasia. J Bone Joint Surg Br 2005;87:1192e6.

[28] Husmann O, Rubin PJ, Leyvraz PF, de Roguin B, Argenson JN. Three-dimensional morphology of the proximal femur. J Arthroplasty 1997;12:444e50.

[29] Rubin PJ, Leyvraz PF, Aubaniac JM, Argenson JN, Estüve P, de Roguin B. The morphology of the proximal femur: a three dimensional radiographic analysis. J Bone Joint Surg Br 1992;74:28e32.

[30] Harris WH. Traumatic arthritis of the hip after dislocation and acetabular fractures: treatment by mold arthroplasty. An end-result study using a new method of result evaluation. J Bone Joint Surg Am 1969;51:737e55.

[31] Engh CA, Bobyn JD. The influence of stem size and extent of porous coating on femoral bone resorption after primary cementless hip arthroplasty. Clin Orthop Relat Res 1988;231:7e28.

[32] Gruen TA, McNeice GM, Amstutz HC. "Modes of failure" of cemented stemtype femoral components. A radiographic analysis of loosening. Clin Orthop Relat Res 1979;141:17e27.

[33] DeLee JG, Charnley J. Radiological demarcation of cemented socket in total hip replacement. Clin Orthop Relat Res 1976;121:20e32.

[34] Zicat B, Engh CA, Gokcen E. Patterns of osteolysis around total hip components inserted with and without cement. J Bone Joint Surg Am 1995;77:432e9.

[35] Conn RA, Peterson LFA, Stauffer RN, Ilstrup D. Management of acetabular deficiency; long-term results of bone grafting in the acetabulum in total hip arthroplasty. Orthop Trans 1985;9:451.

[36] Brooker AF, Bowerman JW, Robinson RA, Riley LH. Ectopic ossification following total hip replacement: incidence and a method of classification. J Bone Joint Surg Am 1973;55-A:1629e32.

[37] Kaplan EL, Meier P. Nonparametric estimation from incomplete observations. J Am Stat Assoc 1995;53:457e81.

[38] Linde F, Jensen J, Pilgaard S. Charnley arthroplasty in osteoarthritis secondary to congenital dislocation or subluxation of the hip. Clin Orthop Relat Res 1988;227:164e71.

[39] Mulroy WF, Harris WH. Acetabular and femoral fixation 15 years after cemented total hip surgery. Clin Orthop Relat Res 1997;337:118e28.

[40] DiFazio F, Shon WY, Salvati EA, Wilson Jr PD. Long-term results of total hip arthroplasty with a cemented custom-designed swan-neck femoral component for congenital dislocation or severe dysplasia: a follow-up note. J Bone Joint Surg Am 2002;84-A:204e7.

[41] Stans AA, Pagnano MW, Shaughnessy WJ, Hanssen AD. Results of total hip arthroplasty for Crowe type III developmental hip dysplasia. Clin Orthop Relat Res 1998;348:149e57.

[42] Mutlu T, Cicek H, Yalcin N, Kilicarslan K, Tuhanioglu Ü. How do different designs of femoral stem affect total hip arthroplasty applied to Crowe type III and type IV dysplastic hips. Hip Int 2016;26:374e9.

[43] Kawai T, Tanaka C, Ikenaga M, Kanoe H. Cemented total hip arthroplasty with transverse subtrochanteric shortening osteotomy for Crowe group IV dislocated hip. J Arthroplasty 2011;26:229e35.
Sofu H, Kockara N, Gursu S, Issin A, Oner A, Sahin. Transverse subtrochanteric shortening osteotomy during cementless total hip arthroplasty in Crowe type-III or IV developmental dysplasia. J Arthroplasty 2015;30:1019e23.

[45] Charity J, Tsidiris E, Sheeraz A, Howell JR, Hubble MJ, Timperley AJ, et al. Treatment of Crowe IV high hip dysplasia with total hip replacement using the Exeter stem and shortening derotational subtrochanteric osteotomy. J Bone Joint Surg Br 2011;93:34e8.

[46] Hasegawa Y, Iwase T, Kanoh T, Seki T, Matsuoka A. Total hip arthroplasty for Crowe type IV developmental dysplasia. J Arthroplasty 2012;27:1629e35.

[47] Zhu J, Shen C, Chen X, Cui Y, Peng J, Cai G. Total hip arthroplasty with a nonmodular conical stem and transverse subtrochanteric osteotomy in treatment of high dislocated hips. J Arthroplasty 2015;30:611e4.

[48] Kerboull M, Hamadouche M, Kerboull L. Total hip arthroplasty for Crowe type IV developmental hip dysplasia: a long-term follow-up study. J Arthroplasty 2001;16(8 Suppl 1):170e6.

[49] Klapach AS, Callaghan JJ, Miller KA, Goetz DD, Sullivan PM, Pedersen DR, et al Total hip arthroplasty with cement and without acetabular bone graft for severe hip dysplasia. A concise follow-up, at a minimum of twenty years, of a previous report. J Bone Joint Surg Am 2005;87:280e5.

[50] Mu W, Yang D, Xu B, Mamtimin A, Guo W, Cao L. Midterm outcome of cementless total hip arthroplasty in Crowe IV-Hartofilakidis Type III developmental dysplasia of the hip. J Arthroplasty 2016;31:668e75.

[51] Numair J, Joshi AB, Murphy JC, Porter ML, Hardinge K. Total hip arthroplasty for congenital dysplasia or dislocation of the hip. Survivorship analysis and long-term results. J Bone Joint Surg Am 1997;79:1352e60.

[52] Chougle A, Hemmady MV, Hodgkinson JP. Severity of hip dysplasia and loosening of the socket in cemented total hip replacement. A long-term follow-up. J Bone Joint Surg Br 2005;87:16e20.

[53] Kawai T, Tanaka C, Kanoe H. Total hip arthroplasty for Crowe IV hip without subtrochanteric shortening osteotomy e a long term follow up study. BMC Musculoskelet Disord 2014;15:72.

[54] Pakos EE, Stafilas KS, Tsovilis AE, Vafiadis J, Kalos N, Xenakis TA. Long term outcomes of total hip arthroplasty with custom made femoral implants in patients with congenital disease of hip. J Arthroplasty 2015;30:2242e7.

[55] Benum P, Aamodt A. Uncemented custom femoral components in hip arthroplasty. A prospective clinical study of 191 hips followed for at least 7 years. Acta Orthop 2010;81:427e35.

[56] Sakai T, Sugano N, Ohzono K, Lee SB, Nishii T. The custom femoral component is an effective option for congenital hip dysplasia. Clin Orthop Relat Res 2006;451:146e53.

[57] Koulouvaris P, Stafylas K, Sculco T, Xenakis T. Custom-design implants for severe distorted proximal anatomy of the femur in young adults followed for 4 8 years. Acta Orthop 2008;79:203e10.

[58] Akbar M, Aldinger G, Krahmer K, Bruckner T, Aldinger PR. Custom stems for femoraldeformity in patients less than 40 years of age: 70 hips followed for an average of 14 years. Acta Orthop 2009:80:420e5.

[59] Edwards BN, Tullos HS, Noble PC. Contributory factors and etiology of sciatic nerve palsy in total hip arthroplasty. Clin Orthop Relat Res 1987;218:136e41.

[60] Eggli S, Hankemayer S, Müller ME. Nerve palsy after leg lengthening in tota replacement arthroplasty for developmental dysplasia of the hip. J Bone Joint Surg Br 1999;81-B:843e5.

[61] Sonohata M, Kitajima M, Kawano S, Mawatari M. Nerve palsy after total hip arthroplasty without subtrochanteric femoral shortening osteotomy for a completely dislocated hip joint. Open Orthop J 2016;10:785e92.

[62] Li H, Xu J, Qu X, Mao Y, Dai K, Zhu Z. Comparison of total hip arthroplasty with and without femoral shortening osteotomy for unilateral mild to moderate high hip dislocation. J Arthroplasty 2017;32:849e56. 